\title{
DEBATE SOBRE LA IDENTIDAD. HACIA UNA CARACTERIZACIÓN DEL “SELBST” EN EL PENSAMIENTO DE NIETZSCHE DESDE LA PERSPECTIVA DE GIANNI VATTIMO
}

\author{
Daniel Mariano Leiro \\ Universidad de Buenos Aires \\ dleiro@fibertel.com.ar
}

\begin{abstract}
Resumen / Abstract
Este trabajo presenta al ideal nietzcheano del Übermensch interpretado desde la perspectiva "débil" de Gianni Vattimo como alternativa en el sentido de la Verwindung heideggeriana al esquema de la subjetividad moderna. Este ideal se presenta no solo como una de las principales formas de vida en las condiciones tardo-moderna de existencia, sino que es parte de un más ambicioso proyecto que intenta redefinir el antiguo concepto de emancipación en la tradición hegelo-marxista en términos de reducción de la violencia. De este modo se intenta responder a la difícil cuestión de cuál sería el nuevo ideal de humanidad que sería preferible adoptar en la actual condición posmetafísica, cuando ya no es más posible seguir invocando la noción de correspondencia para legitimar el discurso.

Palabras Clave: emancipación, ética, Hegel, Nietzsche, subjetividad, Vattimo, Verwindung.

\section{Debate about the identity. Towards a characterization of "SelBST" in Nietzsche's thought from the Perspective of Gianni Vattimo}

This work presents to ideal of the nieztchean Übermensch interpreted from the perspective "weak" of Gianni Vattimo as an alternative in the sense from heideggerian Verwindung to the pattern of the modern subjectivity. This ideal is not only presented as the form of more capable life for the new late-modern conditions of existence, but also as part of a ambitious project that tries to redefine to the old concept of emancipation of the tradition hegelo-Marxist in terms of reduction of violence. This way, it is tried to respond to the difficult question of why a new humanity ideal would be preferable in the current situation post-metaphysics, when it is no more possible to continue invoking to the notion of correspondence to legitimate the speech.
\end{abstract}

KEY WORDS: Emancipation, ethics, Nietzsche, subjectivity, Vattimo, Verwindug. 
¡Sondern eine neue Gerechtigkeit thut noth! Und eine neue Losung! Und neue Philosophen! Auch die moralische Erde ist rund! Auch die moralische Erde hat ihre Antipoden! Auch die Antipoden haben ihr Recht des Daseins! Es giebt noch eine andere Welt zu entdecken - und mehr als eine ! Auf die Schiffe, ihr Philosophen!

Die fröhliche Wissenschaft

$\mathbb{R A}$ La crisis del humanismo contemporáneo que puede fácilmente verificarse en el mundo radicalmente transformado por la tecno-ciencia, no es un dato más de la sociedad contemporánea. Por el contrario, en la fragmentación que hoy experimenta el hombre de la modernidad tardía se revela un fenómeno de nuestra época. Éste parece confirmar la tendencia de la metafísica como pensamiento del fundamento. Un pensamiento que paradójicamente se encamina, como lo ha visto Nietzsche y, en cierto modo también Heidegger, hacia una disolución del Ser con los caracteres de estabilidad y objetividad que tradicionalmente se le habían asignado a la noción de Grund.

Pero fue Nietzsche el primer pensador antihumanista radical que en la soledad de su tiempo supo anticipar la crisis de la subjetividad metafísica, cuyo cumplimiento para Heidegger se manifestaba explícitamente como falta de fondo ontológico (Boden) y pérdida del sentido en apogeo de la actual racionalización tecnológica del mundo ${ }^{1}$. Esa situación epocal es la última de las formas que asume la crisis más amplia de la noción de fundamento que recorre toda la historia del nihilismo occidental. Para examinar ese acontecimiento seguiremos de cerca en este trabajo la sugestiva lectura de "izquierda" que el filósofo italiano Gianni Vattimo propone del pensamiento heideggeriano. Es sabido que la misma ha surgido de un intento de recuperación de la noción de Verwindug heideggeriana, a pesar de que éste sea un término que el autor de Sein und Zeit rara vez emplea en sus escritos. Lo encontramos en una de las famosas páginas de Holzwege, en Vorträge und Aufsätze, (1954) y también aparece en el primero de los ensayos de Identität und Differenz. Según Vattimo, lo que Heidegger había estado buscando bajo el nombre de Verwindung es una prosecución de la herencia del pasado, que en nada se parece a la Aufhebung dialéctica, para la cual reserva la expresión

1 La acentuación, tal vez con un exceso de "constructivismo" por parte de Heidegger de un Nietzsche "sistemático" ha revolucionado ciertamente el campo de los estudios sobre el filósofo alemán, con su insistencia puesta en leerlo en relación con Aristóteles, es decir, como un pensador de la metafísica, interesado en el problema del Ser, pero en un sentido que lo liga estrechamente a la condición destinal de la tradición humanista europea. En efecto, en los cursos de Heidegger sobre el filósofo alemán publicados en los años 60, así como en el ensayo Quién es el Zaratustra, incluido en Vorträge und Aufsätze, Nietzsche aparece caracterizado como el pensador de la "voluntad de poder", en la que culmina la filosofía de la subjetividad desde Descartes, desplegada en el dominio incondicionado sobre la naturaleza y la sociedad del mundo de la técnica. Para ampliar la lectura heideggeriana de Nietzsche, véase Heidegger, Martin (1961), Nietzsche (2 Vols.), Pfullingen. 
alemana Überwindung. Tampoco se confunde con la decisión de "dejar de lado" un error que caracteriza a la relación con un pasado "muerto" que ya nada más tiene que decirnos. En ambos casos predomina la misma noción metafísica de superación basada en un fundamento. Por el contrario, el sentido de la "superación" que caracteriza al pensamiento ultrametafísico, en contraposición con la metafísica tradicional surge del convencimiento de que ésta última no es un error del que podamos librarnos por un simple efecto de voluntarismo. Lo único que cabe esperar es sobreponerse a ella como quien se recupera de una enfermedad que, sin embargo, se mantiene viva en nosotros en una especie de estado de convalecencia. La posibilidad de sobreponerse a la metafísica tendrá lugar mediante una recuperación-distorsión que caracteriza al "natural" modo de funcionar de toda interpretación. Es un funcionamiento que solo puede ser concebido como un acto de cierta "superposición, violencia, e injusticia", ya que opera activamente seleccionando ciertos elementos sobre otros que podrían ser igual de legítimos. Es así como volviendo la Verwindung en contra de la letra de los textos heideggerianos que, finalmente, parecen apuntar a algo deseable y posible más allá del nihilismo, Vattimo se arriesga a sostener que el pensamiento ultrametafísico que Heidegger habría estado buscando en sus últimos escritos no ha logrado trascender los límites del nihilismo que él mismo había visto ante todo realizado en la filosofía de Nietzsche. Su pensamiento sería entonces la expresión de una época que intenta responder a un llamado a asumir conscientemente la responsabilidad de la metafísica consumada como técnica, en la que del ser como tal ya no queda nada porque se ha convertido en voluntad de poder.

Quizás Nietzsche no ha querido ver en la conciencia que fue paulatinamente dominando la idea de la subjetividad metafísica hasta hegemonizarla por completo bajo la forma del sujeto "cristiano-burgués", un fenómeno esencialmente moderno. Señaló en ella el momento de maduración de los elementos nihilistas en sentido negativo que el hombre occidental venía arrastrando desde el ocaso de la época de la tragedia. En su caso, la crítica es dirigida al desenmascaramiento de la superficialidad de la conciencia como interiorización de la disciplina social productiva del mundo de la Ratio en las obras del llamado período medio o "ilustrado", y se radicaliza todavía más en las notas póstumas.

Sin embargo, siguiendo esa perspectiva "humanista" que Nietzsche explícitamente rechaza, es como se ha intentado leer a su filosofía ya en los años 30, después de las primeras recepciones del Nietzsche literato, crítico de la cultura que había dominado el panorama de las interpretaciones de comienzo de siglo XX. En efecto, la lectura del Übermensch que tiende a interpretarlo del modo más obvio como una intensificación de la esencia del hombre que se ha realizado de una manera imperfecta hasta ahora, en un sentido que confirma y potencia los rasgos de la concepción metafísica del sujeto, preside no solo la aventura nazi de Alfred Baeumler. Desde el punto de vista historiográfico, ha sido la visión que ha dado inicio a la recuperación filosófica de Nietzsche. La influencia de esa visión se extiende a otras posturas historicistas, situadas al parecer en las antípodas, pero que en rigor no vienen sino a confirmar el "equívoco" nazi, como la emblemática lectura de Lukács en Die Zerstörung der Vernunft. Para Lukács, señala Vattimo, el Nietzsche verdadero contra el que se reacciona ha sido siempre el Nietzsche de Baeumler, que intenta presentarnos a la figura del autor del Zaratustra 
como pensador de la decadencia de la cultura burguesa en la época del imperialismo ${ }^{2}$. Incluso la interpretación históricamente más determinante de Heidegger a juzgar por la repercusión que alcanzó en la Nietzsche-Renaissance de fines de los 60 es una lectura que, como la misma interpretación "existencialista" de Jaspers o Lowith que también salió a la luz en aquellos años, se proponía liberar al pensador alemán del peso de la máscara nazi con la que había sido revestida su figura en el pasado. Sin embargo, esta postura tampoco dejaría de pensar a Nietzsche como el filósofo de la época de la conclusión-triunfo de la metafísica que se despliega en el Ge-stell como mundo de la organización científico-total.

Sin embargo, el sentido del prefijo Über que tiene una importancia capital cuando se quiere entender el significado de la figura del hombre del ultra nietzscheano -como creemos con Vattimo se podría traducir la expresión Übermensch- debería ser más marcadamente diferenciada de cualquier perspectiva humanista que tienda simplemente a interpretarla como una forma potenciada de la subjetividad metafísica ${ }^{3}$.

Resulta difícil decir qué cosa podría ser el ultrahombre, puesto que la mayor parte de las afirmaciones nietzscheanas lo ponen en una relación crítica con el sujeto de la metafísica. Pero al menos es claro que la figura del cuerpo que permite advertir la multiplicidad del yo, así como la estructura jerárquica de dominio que liga la hegemonía de la conciencia al mundo de la Ratio, no podría servir ya como una descripción del ser verdadero del hombre en contra de teorías "falsas" de la subjetividad. Y es, por eso, que debería ante todo poder disiparse un equívoco que consiste en creer que al situar la "pequeña razón de la conciencia" en aquel ámbito pretendidamente más amplio, la "Gran Razón del cuerpo", Nietzsche se habría propuesto develar la presencia de un trasfondo más esencial que la conciencia humana. Es cierto que en el libro "De los despreciadores del cuerpo" de la primera parte del Zaratustra, la conciencia, el alma o la razón -que son solo algunos nombres con los que la metafísica ha designado al yo-son desenmascarados como instrumentos del cuerpo para llevar un poco de orden y consistencia a la inocencia del devenir, por la imperiosa necesidad que tiene la vida de manifestarse. Pero sería un error pensar que esta inversión se corresponde con una simple reducción materialista de la conciencia al cuerpo. Si así fuera, Nietzsche no habría hecho otra cosa más que continuar, por otros medios, el mismo esquema metafísico fundado en el resentimiento y la necesidad de justificación que critica, al

2 Vattimo, Gianni, "Nietzsche e l'ermeneutica contemporánea", "Nietzsche, il superuomo e lo spirito dell'avanguardia”, Diálogo con Nietzsche: Saggi 1961-2000. Milan, Garzanti. De Baeumler, Alfred veáse Baeumler Alfred (1931), Nietzsche, der Philosoph und Politiker, Lipsia. De George Lukács se puede consultar Lukács, George (1962). Die Zerstörung der Vernunft, Werke, Band 9, Neuwied am Rhein, Berlin Spandau.

"Aurora" en Diálogo con Nietzsche, op. cit. Véase la referencia a George Bataille y Heidegger al comienzo del capítulo "Nietzsche e al di là del soggetto" en Vattimo, Gianni (1981). Al di là del soggetto: Nietzsche, Heidegger e l'ermeneutica, Milán, Feltrinelli.

También, Vattimo, Gianni (1991) Introducción a Nietzsche (trad. Jorge Binaghi), Barcelona, Península, 1996, p. 96. 
restituir a la "animalidad" como la oscura esencia del hombre allí donde antes primaba la racionalidad y la conciencia.

Pero una interpretación como la que Heidegger ha defendido en sus trabajos sobre Nietzsche solo se podría aceptar, en el mejor de los casos, si se piensa en un escrito juvenil como el Nacimiento de la Tragedia. Allí, un Nietzsche todavía influenciado por el romanticismo de su primera formación, pugnaba por liberar a los elementos vitales, dionisíacos de la subjetividad de la opresión que sobre ella ejercía el racionalismo socrático ${ }^{4}$. Pero, de todos modos, es justo reconocer que aún en el escrito que mencionamos, destaca la presencia de un elemento de liberación que se manifiesta en el desenmascaramiento de la pretensión de la conciencia socrática de erigirse como realidad verdadera; denuncia de una violencia solapada en la que puede verse el comienzo de lo que a partir de Humano, demasiado humano, se convertirá en el centro de la crítica nietzscheana a la metafísica, pero cuya génesis se remontaba ya a la época del Nacimiento de la Tragedia.

Suponer, en cambio, como Karl Lowith ha llegado a sostener, que en un texto de madurez como los "Despreciadores del cuerpo", Nietzsche se hubiera propuesto tan solo reflotar una ontología naturalista de tipo griego, o mejor aún, presocrático en el final de la historia de la subjetividad europea ${ }^{5}$, es desconocer el alcance de la crítica nietzscheana a la ficción del sujeto. En opinión de Lowith, la empresa de Nietzsche estaba irremediablemente condenada al fracaso. Al menos así dan testimonio las inconsistencias en las que el propio filósofo habría caído al tratar de conciliar los significados contradictorios de la doctrina del eterno retorno ${ }^{6}$. Sin embargo, la posición de Lowith aquí parece pasar por alto que la crítica nietzscheana, como en general toda la labor de desenmascaramiento que nuestro filósofo desarrolla a partir de la primera edición de Humano, demasiado humano, no se orienta en función de una reapropiación de la verdadera naturaleza de las cosas, oculta, distorsionada por la metafísica, sino, como señala Vattimo, hacia una "generalización e intensificación" de la producción metafórica de los conceptos y nociones de la metafísica. Se trata, como se puede ver, de la lúcida toma de conciencia del nihilismo activo que se resume en el famoso anuncio de la muerte de Dios. Nietzsche lo ve ante todo realizado en la propia actividad de desenmascaramiento. Esta actividad no podría ser pensada sino como una posible narración de la historia de Occidente. Una narración que pretende mostrar el "origen humano, demasiado humano" de los valores y objetos supremos de la metafísica, poniendo el acento en la reducción de todo pretendido hecho a interpretación. Ese fenómeno era lo que el hombre de la tradición precedente llamado bisheriger Mensch había tratado de desconocer, llevado por los enmascaramientos de la lógica del dominio social, en lo que, sin duda, podría ser considerado como el más grande acto de alienación en la historia de Occidente. Es cierto que este modo fetichista de relacionarse del hombre

Etica dell'Interpretazione, Turin, Rosenberg \& Sellier.

Introducción a Nietzsche, p. 88.

Ídem. 
sujetado de la tradición con los conceptos y nociones de la metafísica ha tendido una indiscutible funcionalidad en la promoción de la productividad y la disciplina social. Precisamente ha posibilitado que una esfera de valores trascendentes se independizaran de sus creadores y se impusieran a los demás individuos como un punto de referencia estable y normativo en vistas a organizar la convivencia pacífica sobre bases más racionales. Pero el carácter contradictorio del proceso de constitución y destitución de la metafísica hace que el dominio desplegado hasta su máxima extensión se vuelva contra sí mismo, liberando a los hombres de la imposición del "mundo verdadero". En efecto, es el mismo proceso de la producción simbólica de los conceptos el que ha propiciado el desarrollo tecnológico y posibilitado con su misma autonomía las condiciones para la liberación de las rígidas estructuras de dominio de la metafísica en las que una humanidad llena de resentimiento y espíritu de venganza contra la vida había encontrado algo de seguridad y consuelo en una época dominada por el miedo a la naturaleza. Pero la necesidad que en otro tiempo había determinado su aparición ya no es imperiosa en un momento histórico en el que la organización de la sociedad permite empezar a vivir menos "mágicamente", afirmando las apariencias, en un mundo completamente desencantado por la tecnociencia ${ }^{7}$.

Al ir paulatinamente desapareciendo ese estado de fuerte dependencia de la naturaleza que hacía necesaria la creencia en valores objetivos, en estructuras dadas del ser, la capacidad de mentir y enmascarar que sostenía la creación del ontos no, comenzó a ponerse de manifiesto y a desarrollarse cada vez más marcadamente fuera de toda funcionalidad vital. Así esta debilitación de las razones que justificaban esa creación dio paso a un proceso de progresiva autonomización de lo simbólico. Esa coherente evolución histórica ha conducido al reconocimiento de que el "mundo verdadero", como enseña el famoso capítulo del Crepúsculo de los Ídolos, acabó convirtiéndose en fábula, porque terminó haciéndose explícita la interpretación que constituía su intrincada trama ${ }^{8}$.

7 Vattimo, Gianni, "Dialettica, differenzia e pensiero debole", Il pensiero debole (1983), Vattimo, G. et Rovatti, P. A, (eds.), Milan, Feltrinelli.

8 Así considerada, parecería que la lógica "nihilista" de la historia de la metafísica parecería tener una estructura teleológica en cierto modo comparable a la dialéctica. Sin embargo, las consecuencias "liberadoras" de la disolución del sentido de la realidad no pueden ser pensadas como un hecho fijado y determinado desde el horizonte necesitarista de la metafísica, como el caso de la Aufhebung hegeliana, que ha servido para interpretar a la filosofía de Hegel como una teodicea, en la que la misma necesidad del "mal" quedaría justificada, más allá del sufrimiento de las generaciones que en concreto lo padecen, como un momento inevitable de la realización del "bien". Por el contrario, la pérdida del sentido de la realidad en el mundo de la organización total puede acaso transformarse en una chance de emancipación que la presente época del ser le concede al hombre como manifestación de una condición "destinal", en el sentido heideggeriano de Geschick, pero puede también revestir ese desolador panorama de racionalización y burocratización que Max Weber había profetizado, y con un tono más apocalíptico la denuncia del "mundo administrado" de la primera generación de la Escuela de Frankfurt, ya que la esencia (Wesen) de la técnica -nos ha enseñado Heidegger- no depende de ella misma, sino a la vez de la respuesta que los 
Ahora bien, en este proceso de "desmitificación" que culmina con el reconocimiento de que el mundo verdadero acabó por convertirse en fábula, el hombre experimenta una instancia de emancipación, en cuanto logra liberarse de la relación fetichista con una "realidad" trascendente. Una realidad pretendidamente "independiente" que en su carácter de punto de referencia fijo y estable termina imponiéndose al deforme sujeto de la metafísica con la fuerza de una voluntad ajena y todo poderosa. Pero el paso de la condición de temor e inseguridad primitiva al "amor por la inseguridad" y el espíritu de aventura en que consiste, al decir de Vattimo, el modo de ser, ultrahumano del hombre, no podría significar una afirmación de la absoluta libertad del Übermensch. Pensar que el ideal de una humanidad liberada propuesto por Nietzsche podría llegar a convertirse en una suerte de realización histórica del hombre que ha podido dejar atrás la alienación en los términos de Marx ${ }^{9}$, sería acaso volver a introducir una forma remozada de dualismo platónico. Por un lado, se distinguiría la existencia sujetada del bisheriger Mensch a las estructuras represivas de la moral y la metafísica tradicional, y, por otro, una existencia libre, en perfecta posesión de sí misma, que así se presentaría como la más elevada expresión del ideal de una humanidad conciliada, definida en términos de autoconciencia, que caracteriza al sujeto pensado en el horizonte de la dialéctica ${ }^{10}$.

Como en cierto modo también parecen indicarlo las vicisitudes del tan poco "real" socialismo real en el siglo XX, y la misma suerte que encarna la figura del revolucionario -acaso otra secularización del trágico destino del mártir cristiano- el ideal del yo reapropiado se revela como otra de las máscaras ideológicas que asume la neurótica actitud del sujeto de la metafísica, en la cual la violencia constitutiva del mundo de la Ratio, se perpetúa ${ }^{11}$. Nietzsche no admite que la superación del bisheriger Mensch

hombres sean capaces de dar al reto que les envía la destinación histórica del acontecer en el despliegue de la ciencia-técnica moderna. Véase Vattimo, G.,"Heideggers Verwindung Moderne" (1992), pp. 52-60.

9 Véase "Nietzsche 1994" y "Il Nietzsche Italiano", en Dialogo con Nietzsche.

10 Al di là del soggetto (1981), op. cit. Véase también la distinción que Vattimo lleva a cabo entre la filosofía nietzscheana y el idealismo, especialmente el idealismo hegeliano en $\mathrm{Il}$ soggetto e la maschera. Nietzsche e il problema della liberazione (1974). Milan, FabbriBompiani, p.276 y ss. No obstante, la obra en la que Vattimo entra más extensamente en discusión con la filosofía de Hegel es La Estética de Hegel de 1970. Vattimo, Gianni., Introduzione all'estetica di Hegel. Corso di estetica dellànno académico, 1969-70, Turín, Giappichelli. Aunque el libro como lo indica el título se centra en los temas de la estética hegeliana, contiene importantes vinculaciones con problemas teóricos como el argumento de la relación sujeto-objeto en el idealismo y la conciliación ser-deber, realidad-libertad. Por razones de espacio no podemos dedicarle a esta obra del profesor de Turín toda la atención que ella merecería. El mejor estudio que conocemos sobre la herencia de la dialéctica en el pensamiento débil de Gianni Vattimo es el de Giovanni Giorgio que se intitula Il pensiero di Gianni Vattimo. GIORGIO, Giovanni, Il pensiero di Gianni Vattimo. L'emancipazione della metafisica tra dialettica e l'ermeneutica. Véase el capítulo "El confronto con Hegel”, p. 93 y ss.

11 Vattimo, Gianni, "La Saggezza del Superuomo”, en Diálogo con Nietzsche, op. cit. 
y con él del dominio de la metafísica tradicional, pueda darse en un sentido crítico o también dialéctico, porque esa alternativa no significaría sino un paso dado todavía al interior de la tradición misma ${ }^{12}$. La manera en la que el Übermensch podrá ir más allá del hombre tal y como ha sido concebido hasta ahora ya no será reapropiándose de la plenitud del sentido, sino sobrepasando la falsificación de los conceptos de la metafísica, mediante el reconocimiento de su carácter interpretativo que la consumación de la lógica nihilista de la metafísica ha puesto en evidencia. En suma, de lo que se trata a partir de ahora es de asumir las nociones y conceptos de los que se vale la voluntad de poder para expresarse, desde la saludable perspectiva del hombre que sabe seguir soñando, sabiendo que todo es sueño, según reza en la célebre metáfora de la Gaya Ciencia. Por eso no puede causar asombro que cuando Nietzsche se refiere al yo como aquella interpretación que logra organizar en un equilibrio provisorio la pluralidad de fuerzas en conflicto del Selbst, no le conceda a esta tesis más valor que el de una interpretación que sirve para pensar a la identidad humana según el modelo de la experiencia hermenéutica. Tal experiencia, señala Vattimo, es concebida por Nietzsche "no como un acceso al ser a través de la remoción de máscaras que a menudo le han sido impuestas, sino como un verdadero acontecer del ser (y en definitiva, como un aumento del ser)"13. Pero sería un error suponer que una argumentación de este tipo podría estar dirigida desde una perspectiva de idealismo empírico o trascendental, como si al decir que todo lo que se da como ser es interpretación, Nietzsche estuviera interesado en demostrar que todo es subjetivo porque, al fin de cuentas, todo es obra del sujeto que piensa la interpretación, la quiere o experimenta. Pero resulta que también el sujeto que interpreta debería ser desenmascarado como algo análogamente producido, un añadido de la imaginación o como se afirma en El ocaso de los ídolos, "una fábula, una ficción, un artificio de las palabras", que no es nada fundante, sino un "efecto de superficie", atrapado también él en un juego de desfondamiento por el cual todo deviene interpretación, incluso esta misma tesis ${ }^{14}$.

La infinitud del proceso hermenéutico es también uno de los temas que Nietzsche ha querido metafóricamente presentar con el pensamiento del Eterno Retorno. Esta figura tiene un atractivo especial para nosotros, no tanto porque se trata de una idea que se apodera casi obsesivamente de la obra del Nietzsche tardío, como ha llegado a sostener Heidegger, que ve en este importante Leitworte, de la última filosofía nietzscheana,

12 Vattimo, Gianni, El fin de la modernidad.

13 Al di là del soggetto (1981), op. cit., pp. 35-36. Se trata de una concepción "debilitada" del ser, como Vattimo la llama, que ha perdido su carácter de estabilidad y presencia, y encuentra un punto de apoyo teórico en la "recuperación distorsionada" en el sentido de Andenken de la noción heideggeriana de la diferencia ontológica, interpretada en forma nihilista, la cual ya había sido anticipada por la propuesta nietzscheana de atribuirle al devenir el carácter del ser.

14 Al di là del soggetto (1981). Il soggetto e la maschera, "Crisi della soggettività di Nietzsche a Heidegger" op. cit., p. 85. Veáse también del mismo autor "La voluntad de poder y el destino del sujeto" en Introducción a Nietzsche, pp. 96-97. 
quizás con un exceso de constructivismo, el "único pensamiento" en torno al cual se articula toda su filosofía ${ }^{15}$. La idea del Eterno Retorno es muy significativa en cuanto guarda una estrecha vinculación con el problema de la constitución de la subjetividad, ya que la transfiguración del hombre no-metafísico hasta llegar a ser lo que es, el ultrahombre, se mide por la capacidad de soportar este terrible pensamiento ${ }^{16}$.

Gianni Vattimo, en su obra Introducción a Nietzsche, ha llamado la atención con notable agudeza acerca del vértigo que este curioso pensamiento provoca en el hombre de la tradición platónico-cristiana. Para este último, la noción de un eterno retorno tiene tal efecto desestructurante que no es nada extraño que para él una idea como ésta pueda resultar casi impensable ${ }^{17}$. Pero lo que hace particularmente difícil su interpretación no es solo el carácter enigmático, incluso para el propio Nietzsche, de muchos de los pasajes en donde la idea del eterno retorno se presenta (el caso paradigmático podría ser tal vez el discurso profético del Zaratustra). Existe también la imposibilidad de integrar en una unidad consistente los contenidos contradictorios de esta idea, acentuados, en diversas formulaciones, desde su primera aparición en el fragmento 341 de la Gaya Ciencia, intitulado "Del más pesado peso". De modo que todo aquel que quiera acercarse al concepto de Die ewige Wiederkehr des Gleichen sin la intención de procurarse una claridad esquemática, no tendrá más remedio que mantener esa tensión irresuelta, respetando así una constante en el modo de filosofar de Nietzsche, cuyo eco resuena con especial intensidad en la doctrina del eterno retorno, posiblemente como en ninguna otra idea creada por el filósofo, a excepción tal vez de la propia noción de voluntad de poder.

Pocos pasajes de la obra nietzscheana ilustran el carácter de ficción de la idea del eterno retorno con símbolos y metáforas de tanta belleza poética como el famoso capítulo "De la Visión y el Enigma"18. Ese capítulo, junto con "De la Redención", podría legítimamente ser considerado como el hilo conductor de todo el Zaratustra, acaso el libro donde el concepto de die ewige Wiederkerhr - ( y no hay que olvidar que en el capítulo "Del convaleciente" el mismo Zaratustra se presenta como "maestro del eterno retorno" )- cobra mayor preponderancia. La imagen de la Visión que luego se revelará como un sueño en la línea apuntada por la Gaya Ciencia acentúa todavía más el carácter de ficción, ultrametafísico de la idea del eterno retorno, porque a diferencia de la primera parte del capítulo, Zaratustra no intenta siquiera explicarla, sino que deja abierto su enigmático significado. Esa situación podría tal vez ayudarnos a descifrar el título del pasaje que comentamos "Von Gesicht und Rästel". Ahora bien, sin pretender negar ninguno de los otros significados que podrían estar implicados en la escena que Zaratustra recuerda después de oír el lejano aullido de unos perros, se podría afirmar

15 "Nietzsche ed il problema della temporalità", en Dialogo con Nietzsche.

16 Introducción a Nietzsche, p. 88.

17 "Nihilismo, eterno retorno y decisión", en Introducción a Nietzsche, pp. 77-82.

18 Para ampliar el comentario de estos fundamentales pasajes de la obra Así hablaba Zaratustra, véase de Vattimo. Il soggetto e la maschera, op. cit. p.p 195 y ss. También "La Saggezza del Superuomo" (2000), en Diálogo con Nietzsche, op. cit. 
que uno de los sentidos que parece estar presente en la desagradable figura de la serpiente negra, colgando de la boca del joven pastor, y a punto de sofocarlo, es una idea que sugiere la imposibilidad de trasponer el círculo hermenéutico para alcanzar un referente último en la realidad; un dato inmediato pudiera servir de apoyo al sujeto inseguro, necesitado de fundación, de la tradición.

Es una subjetividad de "cortas miras" e imposibilitada de crear como la que representa la figura del enano "mitad topo; paralítico", que Zaratustra lleva colgado sobre los hombros, mientras intenta ascender por un escarpado sendero de montaña, la que no puede vivir la disolución del sentido como estabilidad trascendente, sino como un espectáculo desesperante y paralizante. Las palabras que este "Espíritu de la pesadez" susurra burlonamente al oído del profeta como un estribillo son en realidad las palabras del nihilismo negativo, propias de un pensamiento que sigue todavía condicionado en una sola dirección por las viejas categorías de la metafísica.

Si seguimos entonces las indicaciones del Zaratustra en las que el ultrahombre aparece definido en términos de libre creatividad de lo simbólico, es fácil advertir que el Übermensch dirige ante todo sobre sí mismo la ironía con la que consigue moverse menos dogmáticamente en un mundo donde se ha vuelto explícito el carácter interpretativo de toda existencia. El ultrahombre es también aquel que reconoce que ninguna de sus decisiones tiene un alcance salvador o culpabilizador total, dado que en ninguna de ellas nunca se juega por entero su verdadero yo ${ }^{19}$. El yo del intérprete no es más que la máscara provisoria de una identidad, el momento de unificación transitoria de las fuerzas en constante disgregación que el Übermensch nunca alcanzará a controlar, precisamente porque la pluralidad que lo atraviesa como individum dividum, sujeto múltiple, son también las fuerzas desapropiadas de los otros, y de las circunstancias siempre cambiantes, sobre las cuales se torna inútil pretender un dominio pleno ${ }^{20}$.

Esta experiencia que el ultrahombre nietzscheano hace de sí mismo como un ser despotenciado de los tradicionales caracteres metafísicos sería otro de los motivos para excluir a su figura de toda confusión con una doctrina de la voluntad de dominio que supone la creencia en el sujeto como punto metafísico último. Por el contrario, el Übermensch no se parece al sujeto violento de la tradición, dueño de sí mismo y con la capacidad de imponerse a los demás en la lucha por el poder, tal como ha querido ver la interpretación nazi-fascista de Nietzsche. Justamente lo que define el sentido positivo del prefijo Über es paradójicamente la capacidad de ir más allá del sujeto de la metafísica y de la necesidad de apropiación que lo caracteriza. Y así este hombre liberado logra vencer toda exigencia de autoconservación, con un ánimo siempre

Vattimo, Gianni, (2000) “Aurora”, en Diálogo con Nietzsche, op. cit.

Aunque con diferencias respecto de la posición de Vattimo, una de las más lúcidas interpretaciones de la idea de constitución de la subjetividad como Zwischen pertenece a la de la especialista argentina en la filosofía de Nietzsche Mónica Cragnolini. Véase en particular su libro Moradas nietzcheanas. Del sí mismo, del otro y del "entre" (2008), Buenos Aires, La Cebra. 
dispuesto a la despedida de lo que en otro tiempo formó parte de la narración de su vida, sin los dramas del sujeto íntimamente marcado por la enfermedad de las cadenas. Precisamente porque el Übermensch es el hombre capaz de vivir hasta el fondo la precariedad y provisionalidad de su existencia superficial sin necesidad de creerla verdadera en el sentido metafísico de la palabra, puede asumir una actitud de apertura ante la experiencia de la pluralidad liberada del mundo en el que la realidad se aligera, porque ya no ofrece el contraste de verdad y apariencia que ha servido siempre para justificar autoritarismos de todo tipo ${ }^{21}$.

Sin embargo, esa forma de entender la subjetividad, no como sustancialidad determinada, sino como capacidad de experimentación, jamás podría convertirse en una nueva y más sólida fundamentación del hombre, ya que el mismo desenmascaramiento de la superficialidad de la conciencia, la cual no será desmentida ni criticada por no ser verdadera, sino por haberse convertido en una ficción anquilosada, ha puesto en evidencia la imposibilidad de alcanzar una más segura fundamentación de la subjetividad por la vía de una simple toma de posición teórica. De todos modos, pese a la dificultad que trae consigo la disolución de la noción de verdad y del ser como fundamento, todavía sigue siendo posible para nosotros redoblar la apuesta por el ideal de una humanidad "liberada" como el que se dibuja en los últimos escritos de Nietzsche. Solo que esa elección del ideal del ultrahombre como intérprete que vuelve a describir el mundo según modelos que ha "elegido" conscientemente en el sentido antes mencionado del aforismo 54 de la Gaya Ciencia, no está solamente justificada por la experiencia histórica de un mundo en el que la comunicación intensificada ha vuelto imposible seguir pensando al hombre en términos de una libre capacidad de decisión y manipulación ${ }^{22}$. A esa atendible razón que, al parecer, se verifica en la experiencia histórica del hombre en la época de la conclusión-triunfo de la metafísica, habría que añadir el hecho de que el Übermensch pensado como una posible superación de la condición destinal de nuestra época aparece, ante todo, como el resultado de una decisión ética, como la que ha inspirado a las voces más críticas de la metafísica del siglo XX, que han planteado la necesidad de superarla. Como señala Vattimo, lo que Heidegger ha llamado "Gestell" como imposición del sistema de la organización científico-total del mundo, con sus consecuencias negativas sobre la singularidad, y que Adorno, retomando algunas de las características de la planificación, llama "mundo administrado", es acaso la manifestación histórica más consecuente de la mentalidad objetivante llevada hasta su máxima expresión que se despliega en la tendencia de la metafísica a identificar el ser con el darse del objeto en la perentoriedad de la presencia.

Nacido en una época en la que la naturaleza, aún no dominada por la técnica, se presentaba como una terrible amenaza para el hombre, el pensamiento del fundamento no podía sino erigirse de otro modo que no fuera como un pensamiento violento. Un pensamiento que paradójicamente revela su profunda inseguridad de base ante la

21 "La Saggezza del Superuomo", op. cit.

22 Vattimo, Gianni (1989). Etica dell'interpretazione, op. cit., p. 93 y ss. 
cual reacciona con un exceso de violencia, y termina imponiéndose con la fuerza de una "autoridad frente a la cual solo cabe el silencio y quizás también una muestra de admiración" 23 .

Pero quienes después de la consumación de la historia de la compleja visión metafísica del mundo que concluye provisionalmente con el anuncio de la muerte de Dios como el devenir superfluo de todas las explicaciones últimas se han mostrado sensibles a las consecuencias de la experiencia histórica de la violencia metafísica - (que es quizás la única manera de definir la violencia derivada del pensamiento del fundamento, sin caer en una nueva metafísica)-, lo han hecho llevados más por motivos de orden ético que teórico ${ }^{24}$. Ese espíritu de rebelión contra los efectos negativos de la racionalización moderna se convierte en un hilo conductor que nos permite encontrar parecidos entre la "vuelta" (Kehre) heideggeriana con las críticas de Derrida y Levinas, pasando por el propio Vattimo, hasta la denuncia adorniana de la violencia del concepto, el Bloch del Espíritu de la Utopía, o el Lukács, crítico del proceso de reificación en la sociedad capitalista. De uno u otro modo, se percibe en el sentido del ser pensado con los caracteres de la tradición un límite insuperable para las posibilidades del pensamiento y de la acción del hombre, más allá del cual no se puede ir. En esta misma dirección se puede decir que apunta la experiencia constitutiva del Übermensch que se caracteriza negativamente también por la imposibilidad de presentarse como una clara solución alternativa a la idea de la subjetividad metafísica. El ultrahombre es más bien la expresión de un ideal de emancipación que no puede ser ya definido en los términos modernos de autodeterminación, sino como disolución de las razones que justifican y hacen posible la violencia metafísica ${ }^{25}$.

Pero no se trata ya de repetir con otros nombres el mismo juego del cual la crítica quería apartarse por medio del desenmascaramiento de la superficialidad no reconocida de la metafísica. También la decisión de oponerse a ella es asumida en su carácter radicalmente ultrametafísico como lo que es: una posible respuesta que nace de un ejercicio consciente de la hybris hermenéutica al modo de darse histórico-destinal del ser en el mundo tardomoderno. Esta decisión que mueve a hacer una apuesta por el ideal de una humanidad liberada en los términos propuestos por el Übermensch no puede ser sino una decisión arriesgada, que busca ponerse a la altura de un pensar que, prestando también un oído atento a las enseñanzas del Heidegger maduro, quiere llevar hasta sus últimas consecuencias el desafío de "dejar marchar al ser como fundamento". Se trata de una actitud que ya no siente la necesidad de seguridad propia del sujeto de la metafísica. Por el contrario, es capaz de recorrer hasta el final la experiencia del nihilismo, y salir de ella transfigurado como el joven pastor en la visión de Zaratustra, que se levanta iluminado por una luz nueva, y riendo con una risa que la humanidad no

Vattimo, Gianni (1992), Más allá de la Interpretación (trad.de Pedro Arangón Rincón), Barcelona, Paidós, p. 37.

Ibíd. p. 38.

"La Saggezza del Superuomo", op. cit. 
conoció jamás, porque ha aprendido a vivir creativamente y sin nostalgias reactivas, el hundimiento de la existencia en el abismo de la desfundamentación (Abgrund).

\section{Referencias bibliográficas}

Baeumler Alfred (1931), Nietzsche, der Philosoph und Politiker. Berlin: Lipsia.

Cragnolini, Mónica (2008), Moradas nietzcheanas. Del sí mismo, del otro y del "entre". Buenos Aires: La Cebra.

Giorgio, Giovanni (2006), Il pensiero di Gianni Vattimo. L'emancipazione della metafisica tra dialettica e l'ermeneutica. Milan: Franco Angeli.

Heidegger, Martin (2003), "Identität und Differenz", Gesamtausgabe I. Abteilung: Veröffentlichte Schriften, Band 11, Frankfurt am Main: Vittorio Klostermann. (1961), Nietzsche (2 Vols.). Pfullingen: Editorial Günther Neske. (2006), Sein und Zeit. 19. Auflage. Tübingen: Niemeyer.

(2003), "Vorträge und Aufsätze", Gesamtausgabe I. Abteilung: Veröffentlichte Schriften, Band 7. Frankfurt am Main: Vittorio Klostermann.

Lukács (1962), "Die Zerstörung der Vernunft” Werke Band 9. Neuwied am Rhein, Spandau, Berlin.

Vattimo, Gianni (1970), Introduzione all'estetica di Hegel. Corso di estetica dellànno académico, 1969-70. Turin: Giappichelli.

(1974), Il soggetto e la maschera. Nietzsche e il problema della liberazione. Milan: Fabbri-Bompiani.

(1981), Al di là del soggetto: Nietzsche, Heidegger e l'ermeneutica. Milan: Feltrinelli.

(1983), "Dialettica, differencia e pensiero debole", Il pensiero debole. Vattimo, G. et Rovatti, P.A., (eds.). Milan: Feltrinelli.

(1991), El fin de la modernidad: nihilismo y hermenéutica en la cultura posmoderna, trad. Alberto Bixio. Barcelona: Gedisa, 1996.

(1989), Etica dell'interpretazione. Turin: Rosenberg\&Sellier.

(1991), Introducción a Nietzsche, trad. de Jorge Binaghi. Barcelona: Península.

(1992), "Heideggers Verwindung Moderne", Martín Heidegger. Denker der Post-Metaphysik. Ed. par Veauthier, F. W. Heidelberg: Carl Winter Universitätsverlag.

(1995), Más allá de la interpretación, trad. de Pedro Aragón Rincón. Barcelona: Paidós. (2000), Diálogo con Nietzsche: Saggi 1961-2000. Milan: Garzanti. 